\title{
Character Strengths of Airline Pilots: Explaining Life and Job Satisfaction and Predicting CRM Performance
}

\author{
Hadassah Littman-Ovadia*, Elad Raas-Rothschild" \\ Ariel University, Ariel, Israel \\ Email: ^hadassaho@ariel.ac.il
}

How to cite this paper: Littman-Ovadia, H., \& Raas-Rothschild, E. (2018). Character Strengths of Airline Pilots: Explaining Life and Job Satisfaction and Predicting CRM Performance. Psychology, 9, 2083-2102. https://doi.org/10.4236/psych.2018.98119

Received: July 13, 2018

Accepted: August 7, 2018

Published: August 10, 2018

Copyright $\odot 2018$ by authors and Scientific Research Publishing Inc. This work is licensed under the Creative Commons Attribution International License (CC BY 4.0).

http://creativecommons.org/licenses/by/4.0/

\begin{abstract}
The associations of character strengths with job satisfaction and work performance have recently been studied. However, the questions whether different professions are characterized by different strengths, and whether different strengths explain desired outcomes in different professions remain unresolved. The present study sought to identify the character strengths most highly endorsed by airline pilots and most highly used in a typical pilot's workday. The study also aimed to determine which strengths are most highly associated with pilots' life and job satisfaction, and most predictive of specific work performance. Israeli airline pilots $(N=177)$ completed measures of strengths endorsement, strengths use, life satisfaction, and job satisfaction. Participants' crew resource management (CRM) behaviors were assessed to reflect actual job performance. Findings pointed to various character strength profiles related to the examined personal and work aspects. These findings highlight the contribution of specific strengths to satisfaction and performance of airline pilots. Implications regarding the potential interaction between organization culture and personal strengths are addressed.
\end{abstract}

\section{Keywords}

Character Strengths, Airline Pilots, Life Satisfaction, Job Satisfaction, CRM Skills, Job Performance

\section{Introduction}

Character strengths reflect durable positive individual capacities for feeling,

\#The second author is an M.A. student in Psychology at Ariel University and an airline pilot, serving as first officer at $\mathrm{El} \mathrm{Al} \mathrm{Israel} \mathrm{Airlines} \mathrm{Ltd.}$ 
thinking, and behaving in ways that allow optimal functioning and performance in the pursuit of valued and desired outcomes (Linley \& Harrington, 2006) that enable growth and flourishing of individuals and organizations (Peterson \& Seligman, 2004). Character strengths have been associated with life satisfaction (Peterson, Ruch, Beermann, Park, \& Seligman, 2007), well-being (Seligman, 2011), positive affect (Littman-Ovadia \& Lavy, 2012a), coping (Brooks, 2010), and with various aspects of work lives (e.g., Forest et al., 2012; Harzer \& Ruch, 2012; Littman-Ovadia \& Lavy, 2012b, 2016; Littman-Ovadia \& Steger, 2010; Peterson, Stephens, Park, Lee, \& Seligman, 2010; Smith, 2011).

Since its development, the VIA character strengths classification (Peterson \& Seligman, 2004) has provided fertile ground for research examining two main questions: what are the most commonly endorsed and most dominant strengths across different cultures and what are the strengths most substantially associated with different aspects of well-being, including life satisfaction. Addressing the first question, Park, Peterson and Seligman (2006) reported that the strengths most frequently ranked as the personally first strength across 5299 adults from 54 different countries were integrity, fairness, kindness, curiosity and critical thinking. On the other hand, the strengths most frequently ranked last across these countries were prudence, modesty, self-regulation, spirituality, and zest (Park et al., 2006). These findings were replicated eight years later, using a sample of more than one million participants from 75 nations, supporting substantial cross-cultural similarity in the endorsement of character strengths (McGrath, 2015). Regarding the second question, several studies (e.g., Park, Peterson, \& Seligman, 2004; Park \& Peterson, 2008) have identified the strengths of hope, zest, gratitude, love, and curiosity as most substantially related to life satisfaction. Moreover, in a longitudinal study, these five strengths foreshadowed life satisfaction measured months later, even when their initial levels were controlled (Park \& Peterson, 2008).

These two questions also have relevance to the work domain, and have indeed been examined in recent years. Money, Hillenbrand and Camara (2009) addressed the first question, surveying a small sample of 60 middle to senior managers from 30 different organizations in western Europe, who were asked about the extent to which strengths are expressed in their work ("I express this strength a lot in my work"). The assessment revealed that the top five (starting with highest) strengths expressed at work for these managers were integrity, critical thinking, perspective, fairness, and perseverance. They also found that the bottom five (starting with lowest) strengths expressed at their work were spirituality, appreciation of beauty and excellence, love, bravery, and modesty. It should be noted that they did not examine the strengths that the managers actually possessed, but rather how much the managers estimated their expressing strength in the course of their work.

Regarding the second question, a number of studies have identified specific strengths from the VIA classification that best explain job satisfaction as an indicator of well-being in the work domain. For example, in seeking out strengths 
associated with job satisfaction, Peterson, Stephens, Park, Lee and Seligman (2010) revealed zest, hope, curiosity, gratitude, and spirituality, while Smith (2011) identified zest, hope, and social intelligence. Some studies went beyond job satisfaction, providing support for positive effects of strengths on work performance, albeit also by self-report assessment. For example, Engel, Westman and Heller (2012) identified signature strengths as contributors to work performance, but it was not clear which specific strengths function as the source of these effects, as the configuration of signature strengths differed across individuals. Littman-Ovadia and Lavy (2016) highlighted the contribution of perseverance to work performance and counterproductive behaviors, beyond the role played by other character strengths. They indicated perseverance, integrity, hope, zest, and social intelligence as the character strengths most highly associated with work performance. Littman-Ovadia and Lavy (2016) also found perseverance, zest, integrity, and hope as four of six character strengths, whose low endorsement were the best predictive of counterproductive behaviors (the other two were self-regulation and teamwork). However, these studies explain job satisfaction and work performance across employees from diverse occupations, albeit neglecting occupation-specific strengths.

Going from the broad domain of the world of work to focusing on specific occupations reveals only a handful of studies that sought to identify the most dominant strengths on specific occupations and examined the specific strengths associated with employees' satisfaction and performance. Peterson and Park (2006) briefly reported associations between teachers' social intelligence and their students' performance, and Lim and Kim (2014) found that restraint and interpersonal strengths predicted teachers' personal teaching efficacy reports. Peterson et al. (2010) showed that workers in a given occupation scoring higher on a strength which is less typical for that occupation were more likely to be satisfied with their work. In a study comparing two distinct occupations, both in strengths endorsement and associations with life satisfaction, Littman-Ovadia and Lavy (2012b) found notable differences between youth leaders and police investigators. Though there was some overlap in these groups' self-rated signature strengths (e.g., love), the only dominant strengths identified by more than $30 \%$ of the youth leaders were kindness, spirituality, and gratitude, while the only dominant strength identified by more than $30 \%$ of the police investigators was integrity. Furthermore, the strengths correlating with life satisfaction differed somewhat among the two groups: For the youth leaders, hope, zest, social intelligence, love, and bravery were the strengths most highly associated with life satisfaction, while for the investigators, self-regulation, integrity, zest, leadership, and teamwork were those most highly linked to life satisfaction. This study suggests that different occupations might prioritize different strengths and that different strengths might be connected to life satisfaction. All these findings highlight the need for further strengths research on specific occupations. More precisely, absent from the literature is a study examining which specific strengths 
are the most important for job satisfaction and actual job performance in specific occupations.

The specific profession chosen for the current study was commercial airline pilot. The aims of the present study were to identify the most dominant strengths among airline pilots, to examine whether these strengths are the most deployed in their typical work day, and to identify the strengths most highly associated with life satisfaction and job satisfaction, and the strengths most highly predictive of actual performance in commercial flights.

\subsection{The Characteristics of a Good Airline Pilot}

As reflected from selection tests used over the years, various factors have been perceived as being important in order to become a good airline pilot in civil aviation, as the prediction of pilot performance has played a prominent role in aviation psychology for over half a century. Over the years, research has shown that cognitive, psychomotor, and biodata instruments have been among the best predictors of pilot performance, whereas the traditional personality measures have tended to be less predictive. Today, the required and desirable characteristics of a good pilot are viewed as both technical and non-technical (Nergard, 2014). The non-technical qualities include motivational, personal, and interpersonal aspects, all being related to flight safety, the most important value for airline pilots. Flight safety is an individual responsibility: Each pilot is morally and ethically obligated to perform as safely as possible, and to take responsibility for his or her actions (Nergard, 2014).

In the world of civil aviation, there is a direct link between performance and safety. Pilots who do not perform their duties at an excellent level may bring themselves and the passengers to disaster (Oster, Strong, \& Zorn, 2013). As the cost of a mistake is enormous, the airlines have instituted several periodic mechanisms for maintaining an excellent performance level. European Aviation Safety Agency (EASA) and the Federal Aviation Administration (FAA) regulations require simulator training twice yearly, mainly dealing with malfunction handling, aircraft maneuvering, and decision making, all carried out with a full cockpit crew, thus demanding good crew coordination. Pilots are required to pass an annual line check (an inflight exam done on a regular commercial flight), where their standard operation, basic flying, compliance with company and law regulations, and crew coordination are measured. This examination is administered in addition to annual written exams tapping aviation knowledge.

However, despite the enormous importance of performance quality, the ability of airlines to measure actual pilot performance subsequent to the initial training phase is often limited (Weber, Mavin, Roth, Henriqson, \& Dekker, 2014). For instance, while a pilot is evaluated in the event of a malfunction or an extreme condition requiring the maximum use of the pilots' and crews' abilities to safely land the aircraft, these events are quite rare and are experienced by very few pilots. Furthermore, the grade distribution on the periodic simulator tests (pass, fail, and excellent) reflects a ceiling effect, which greatly constrains its perfor- 
mance measurement capability, with performance typically correlated with the experience of the pilot on the specific aircraft (Campbell, Castaneda, \& Pulos, 2010).

Pilots' performance level comprises both the level of flight functions (ability to correctly fly an aircraft and the extent of aviation knowledge) and the degree of interpersonal functioning. Most of the research involving performance assessment in aviation has been carried out in military settings, and a large part of it has focused on psychomotor skills and abilities (Carretta, 1989; Carretta \& Ree, 2003). Many researchers have also sought to understand the personality factors contributing to the predictability of a pilots' success in the military, but there seems to be no clear and consistent evidence as to what is the appropriate personality profile for an excellent pilot (Carretta et al., 2014; Martinussen, 1996). Research in the personality and interpersonal fields of the flight profession is lacking, and only in recent years has it begun to gain momentum (Nergard, 2014; Nergard, Hatlevik, Martinussen, \& Lervag, 2011).

Nergard and his colleagues (2011) formulated the elements that define a "good pilot", based on pilots' own perspective. They identified four key elements: knowledge, teamwork, self-awareness, and flying skills. A key finding in the research was the common use of the term airmanship, the response given by pilots upon being asked to describe a "good pilot".

Nergard went on to study the concept of airmanship, and in 2014, he published a study that explored the questions: what defines a pilot characterized by good airmanship and why having good airmanship is important for an aviator. Airmanship was linked by the pilots to being a safer pilot and to causing fewer safety events. A pilot having good airmanship is one who can integrate aeronautical theory with practical flying skills, and is capable of applying them when needed. Another issue raised in Nergard's study is the need for good teamwork, or as this concept is defined in the aviation world: crew resource management (CRM). In other words, it was further suggested that in order for pilots to apply their knowledge in real time, they must work with their crew member at a high level of coordination.

\subsection{Character Strengths of Airline Pilots}

As proposed by Nergard (2014), a good pilot needs to have good personal and interpersonal qualities. On the personal side, pilots need three character strengths: integrity (being honest, speaking the truth, presenting oneself in a genuine way, and acting sincerely, without pretense, and taking responsibility for one's feelings and actions); critical thinking (thinking things through and examining them from all sides, not jumping to conclusions, being able to change one's mind in the presence of evidence, weighing all evidence fairly); and perseverance (completing what one begins, persevering in a course of action despite obstacles, "getting it out the door", taking pleasure in completing tasks). Honesty and integrity are expressed in the initial stage of debrief, in which pilots are 
required to understand what transpired in flight, and what went wrong. In order for pilots to progress and improve, they must investigate the truth objectively, ignoring the discomfort of in acknowledging the error. The second stage of the standard debrief requires a critical examination (critical thinking) of the processes and actions performed by the pilots as an individual or as a member of a crew. The pilots must understand for themselves, with the help of their colleagues and with external aids (such as video, voice and data recording) what went wrong, and what they must do differently in order to improve. Finally, in order to enhance their subsequent performance, they must indicate specific actions to be implemented on their next flights. As pilots may not always be successful on their first and second efforts, pilots are required to continue and strive for the perfect performance, thus, perseverance is required.

On the interpersonal side, Nergard's (2014) research showed that pilots appreciate personal qualities and skills that facilitate proper teamwork, where all crew members can freely express themselves. Pilots surveyed in the study claimed that every pilot in a crew should seek to understand what is transpiring in each crew member's inner world, as well as in their own, and how to allow each of the crew members to express themselves. Therefore, a good pilot would need the character strength of social intelligence (emotional and personal intelligence, being aware of the motives and feelings of others and oneself, knowing how to fit into different social situations) and teamwork (social responsibility, loyalty, working well as a member of a group or team, being loyal to the group, doing one's share). In addition, every response and every reaction to others' responses should come from a place of personal and emotional self-management. For example, a single non-managed response could silence an entire crew, creating a silence that may remain unbroken, even in the face of an extremely dangerous occurrence. An investigation of safety incidents and past accidents revealed that in situations where crew members should have spoken out and even shouted, they stood idly by and kept silent (Bienefeld \& Grote, 2012). From the above, we can see that self-regulation (self-control, regulating what one feels and does, being disciplined, controlling one's appetites and emotions) is another important component in this complex process.

Nergard (2014) and others (Ashcraft, 2005; Orasanu, Fischer, \& Davison, 1997) suggested that leadership (encouraging a group of which one is a member to get things done while maintaining good relations within the group, organizing group activities and seeing they are executed) is a required character strength, especially at the stage where the pilot functions as a captain. In civil aviation, most decisions are made when the time component is not urgent, allowing the captain and crew to take well-informed decisions, following consultations with all relevant crew members. When a decision is made in the absence of a consensus, the captain must demonstrate leadership in problem solving, decision making, and action implementation.

More than ninety percent of Israeli airline pilots have served or still serve (as 
reservists) as active pilots in the Israeli Air Force. While one could suppose that the work of military and civilian pilots is fairly analogous, this is not the case (Haavik, Kongsvik, Bye, Royrvik, \& Almklov, 2017). Military flights are mission-oriented, while civilian flights are safety-oriented. Although bravery (not shrinking from threat, challenge, difficulty, or pain; speaking up for what's right, even in the face of opposition; acting on convictions, even when unpopular) is a highly valued strength in the army, civil aviation has no place for bravery, which could even drive a pilot to act recklessly. Prudence (being careful about one's choices, not taking undue risks, not saying or doing things that might later be regretted), on the other hand, may be the main character strength to replace bravery for civilian pilots.

Thus, we posit the following hypotheses:

H1-H2: Integrity, critical thinking, perseverance, social intelligence, teamwork, self-regulation, leadership, and prudence will be the character strengths most endorsed and most used by Israeli airline pilots.

A second issue requiring study is identifying the strengths most highly associated with life satisfaction and job satisfaction among airline pilots. Given that this is the first study to examine pilots' strengths, we will assume that their life satisfaction strengths are no different from those of the general population, while their job satisfaction as an airline pilot will be associated with the strengths that characterize their profession. Thus, we posit the following hypotheses:

H3: Love, hope, gratitude, curiosity, and zest will be the character strengths most highly associated with life satisfaction of Israeli airline pilots.

H4: Integrity, critical thinking, perseverance, social intelligence, teamwork, self-regulation, leadership, and prudence will be the character strengths most highly associated with job satisfaction of Israeli airline pilots.

The final issue to be examined in this study is identifying the specific strengths which can predict actual performance during commercial flights.

\subsection{CRM Behaviors as a Desired Performance of Airline Pilots}

A turning point in airlines' perspective on desirable pilot behavior occurred on March 27, 1977, when 583 people were killed on the island of Tenerife in the biggest air disaster in history, when two Boeing 747 collided on the ground. The accident was traced to many factors, including bad weather, commercial pressures, and poor coordination with the air traffic controller. A second thread linking all the above circumstances to the fatal event was the absence of teamwork in the cockpit of the Dutch KLM aircraft involved in the accident. In this case, the experienced captain with a key role in the company flew with a young, inexperienced first officer and an insecure flight engineer. All the captain's decisions were taken unilaterally, without considering other statements voiced in the cockpit. Due to the captain's unpleasant verbal tone, the rest of the crew did not express their views, and finally, he took off without the approval of the control tower, with a Pan American airplane taxiing on the runway. This incident totally 
changed aviation flight safety. There was a need for a change in pilot training concerning teamwork inside and outside the cockpits, leading to the creation of the field of crew resource management (CRM).

The very fact that safety investigators now began examining the way crews communicate and act as people was a significant change. Aviation safety research began focusing on the personal level, examining how the pilot's inner world affects interpersonal interaction. CRM principles and interventions have been adopted also in occupations involving crews working under time pressures and where error cost is high, such as in firefighting and rescue teams (Okray \& Lubnau, 2003; Flin, O'Connor, \& Mearns, 2002), and medical crews in surgery, intensive care, and delivery rooms (Pizzi, Goldfarb, \& Nash, 2001).

CRM training is now part of commercial airline license prerequisites, and airline pilots are required to undergo periodic workshops to maintain their CRM capabilities. In these workshops, the participants learn about flight psychology by means of debriefing segments taken from actual flights and incidents. Together, participants learn about the interaction of their inner world of thoughts and feelings with their crew members' thoughts and feelings. Today, there is an understanding in the aviation world that interpersonal and self-management skills are at least as important to pilots as psychomotor skills and academic skills (Hedge et al., 2000; Nergard, 2014).

Hedge and his colleagues (2000) designed a scale to measure teamwork skills for the US Army classification system, known as STARS (Situational Test of Aircrew Response Styles). Hegde et al. interviewed both "expert" pilots, serving as instructors and reservists, and "beginner" pilots, just starting to fly at the flight academy. The pilots were asked to describe what makes a good crew leader and what makes a pilot a good CRM pilot (having good teamwork skills). Seven areas were found to reflect behavior that encourages proper teamwork: 1) facilitating teamwork, 2) responsibility and accountability, 3) motivating and educating crewmembers, 4) training and coaching crewmembers 5) coordinating and directing crewmembers, 6) facilitating information flow, 7) problem solving and decision making.

Despite Hedge et al.'s (2000) work having been abundantly cited, no psychometric properties of the scale have been made available. STARS, as a tool used in the US military, may yield different results in the civil aviation setting. STARS relies on self-report and is used as a screening tool for flight academy candidates, but does not tap skills characterizing a trained, working pilot, and thus, does not enable giving constructive feedback to that pilot.

In the current study, we aimed to examine specific, self-reported character strengths as predictors of positive CRM behaviors, which were assessed by crew colleagues immediately after landing. Based on the aforementioned theoretical and conceptual links between character strengths and CRM, we posited the following hypothesis:

H5: Curiosity, leadership, zest, and social intelligence will be the best character strengths predictors of CRM actual behaviors. 


\section{Method}

\subsection{Participants and Procedure}

The study's sample comprised 177 Israeli airline pilots ( $N=174,98.3 \%$ males). Participants' age ranged from 30 to $74\left(M_{\text {age }}=47.35 ; S D_{\text {age }}=9.53\right)$. Most of the participants $(n=156,88.1 \%)$ were born in Israel; the rest were born in the USA ( $n=2,1.1 \%)$, Europe $(n=12,6.8 \%)$, the Soviet Union $(n=3,1.7 \%)$, or in South America $(n=4,2.3 \%)$. Of the study participants, $12.4 \%(n=22)$ had a high school education, $52.5 \%(n=93)$ held a bachelor's degree, $33.3 \%(n=59)$ held a master's degree, and $1.7 \%(n=3)$ held a Ph.D. The vast majority of the participants served in the Israeli Air Force $(n=162,91.5 \%)$, as fighter pilots $(n=73$, $41 \%)$, transport pilots $(n=48,27 \%)$, helicopter pilots $(n=39,22 \%)$, with two participants not reporting on the nature of their army service. The total number of years of experience in flight ranged from 6 to 49, with an average of 27.65 years $(S D=9.99)$. Almost all of the participants worked as pilots for $\mathrm{El} \mathrm{Al} \mathrm{Israel}$ Airlines $(n=170,96 \%)$, and the rest of the pilots work for Arkia (1), Israir (2), CAL (3) and the aeronautical industry (1) .

Participants were recruited by an e-mail sent from the Israel Air Line Pilots Association providing an explanation of the study and an informed consent form. Attached to the e-mail was a link to complete the Strengths Deployment Measure (SDM; Littman-Ovadia \& Steger, 2010), Satisfaction with Life Scale (SWLS, Diener, Emmons, Larsen, \& Griffin, 1985), Job Satisfaction Questionnaire (JSQ; Andrews \& Withey 1976), and a questionnaire requesting demographic, aviation experience, and background information on Google Forms ${ }^{\mathrm{Tt}}$. The participants then completed the 120-item shortened Hebrew version (VIA-120; Littman-Ovadia, 2015) of the Values in Action Inventory of Strengths (VIA-IS; Peterson \& Seligman, 2004) questionnaire through the VIA website. Due to a low response following the initial distribution of the Israel Air Line Pilots Association's e-mail, the second author contacted company pilots by means of general mailing groups using Google Groups ${ }^{\mathrm{Tw}}$, encouraging them to participate in the research. In addition, a voucher for a pair of sunglasses (valued at NIS 500) was raffled among participants as an incentive to participate in the research.

For the second phase of the study, immediately after landing, pilots were contacted by the second author and asked to complete the Pilots Crew Resource Management (CRM) Behaviors Peer Assessment, for a crew member who had participated in the first stage of the study and who had just flown with them. The purpose of the study was once again explained, emphasizing that the reported information was not to be shared with the airlines, and that the use of the information was for research purposes only. Each peer assessor was provided with a link leading to a Google Forms ${ }^{\mathrm{TM}}$ questionnaire consisting of an informed consent form and the Pilots Crew Resource Management (CRM) Behaviors peer assessment. 


\subsection{Measures}

Character strengths. The Values in Action Inventory of Strengths (VIA-IS; Peterson \& Seligman, 2004) was used to assess participants' character strengths' endorsement. In the present study, the shortened, 120-item version (VIA-120; Littman-Ovadia, 2015) was used. This shortened version comprises five items for each of the 24 strengths in the VIA classification. For example, the creativity strength is tapped by items such as "Being able to come up with new and different ideas is one of my strong points"; perseverance is tapped by items such as "I never quit a task before it is done." Participants rate the extent to which each item adequately describes them, on a 5-point Likert-type scale, ranging from 1 (not at all like me) to 5 (very much like me). Internal consistencies of the 24 scales were satisfactory (Chronbach's a coefficients for the scales ranged from .77 to .91). Scale scores were averaged across items, yielding 24 scores for each participant, reflecting each participant's ratings of each of the 24 strengths. In addition, the 24 scores of each participant were rated from the highest to the lowest, so that for all subjects, 24 ratings were obtained. The highest strength of the subject was represented by 1 , and the lowest strength in the individual ranking was represented by 24 .

The use of VIA's strengths at work. Strengths use was assessed using the Strengths Deployment Measure (SDM; Littman-Ovadia \& Steger, 2010). This 24-item questionnaire is based on Peterson and Seligman's (2004) list of character strengths. Respondents are presented with a list of the 24 VIA strengths, accompanied by a brief definition for each strength, and are requested to indicate the extent to which they have the opportunity to deploy each of the 24 strengths during their typical work day as civilian pilots. The extent of the use of each strength is rated on a 5-point Likert-type scale, ranging from 1 (very little) to 5 (very much). The questionnaire showed satisfactory internal consistency (Chronbach's $\alpha=.91$ ).

Life satisfaction. Life satisfaction was assessed by the 5-item Satisfaction with Life Scale (SWLS; Diener, Emmons, Larsen, \& Griffin, 1985), tapping general life satisfaction, rated on a 7-point Likert-type scale (sample items: "In most ways, my life is close to my ideal," and "I am satisfied with my life"). The current sample's Cronbach alpha for this scale was 0.85 .

Job satisfaction. Job satisfaction was assessed by two items from the JSQ; Andrews \& Withey 1976, comprising five items rated on a 7-point Likert-type scale, ranging from 1 (terrible) to 7 (delighted). Both questions focus on job satisfaction, specifically from work as an airline pilot: "How do you feel about your job (as an airline pilot)?" and "How do you feel about the work you do at your job (as an airline pilot), the work itself?" $(r=.27, p<.001)$.

Pilots Crew Resource Management (CRM) behaviors. Pilots crew resource management (CRM) behaviors were assessed by six items from the Situational Test of Aircrew Response Styles (STARS; Hedge et al., 2000), a scale designed to measure aircraft pilot performance on the aspects of the job related to crew 
coordination, communication, teamwork, and problem solving. Six items were presented on a 10-point Likert-type scale, ranging from 1 (very low) to 10 (very high): facilitating teamwork, responsibility and accountability, motivating and disciplining crewmembers, training and coaching crewmembers, coordinating and directing crewmembers, and facilitating information flow. A seventh item from the original STARS scale (problem solving and decision making) was not included in the current study, as it taps a personal skill rather than an interpersonal ability. Immediately after landing, each crew member was asked to assess the actual CRM behaviors exhibited by fellow pilot during the flight from which they had just landed (first officers were assessed by captains and captains by first officers). In the course of the current study's data collection, 141 pilots were assessed a single time, 134 were assessed twice (by two different colleagues following two different flights), and 105 were assessed three times (by three different colleagues following three different flights). Internal consistencies were satisfactory for all three measurements (Chronbach's $\alpha$ coefficients ranged between 0.92 - 0.94). Ranks were averaged across items for each evaluation event, with each participant receiving one, two, or three scores, reflecting participants' skills as manifested in the particular flight. Interrater reliabilities, as reflected by correlations between different raters were high $(.78-.85)$. Factor analysis with promax rotation yielded a single factor, explaining $75 \%, 76 \%$, and $72 \%$, of total variance in first, second, and third measurement times, respectively. Therefore, an average of the scores was calculated for those who received more than one score so that a single CRM skills score was obtained for each participant.

\section{Results}

\subsection{The Most and the Least Endorsed Character Strengths by Airline Pilots}

We examined $H 1$ in two ways: by personal ranks and by absolute scores of the 24 strengths. First, VIA strengths scores were computed by rank, ipsatively (see Table 1). That is, for each respondent, we ranked his or her character strength scores from 1 (top) to 24 (bottom). Given that a person who is high on one strength must necessarily be lower on other strengths, ipsative scoring builds dependencies into the data. However, ipsative scoring reduces concerns about response bias and enables the identification of the top personal five ranked strengths, termed signature strengths (Peterson \& Seligman, 2004).

We found that the strengths most frequently endorsed as signature strengths (being in the individual's five highest strengths, ranked 1 - 5) by the pilots, as can be seen in Table 1, were integrity (62.7\%), critical-thinking (43.5\%), prudence $(39.5 \%)$, love $(39.0 \%)$, fairness $(38.4 \%)$, creativity (32.8\%), perseverance (27.1\%), teamwork (22.6\%). As hypothesized, integrity, critical thinking, prudence, perseverance, and teamwork were included among the eight top signature strengths of airline pilots. However, social intelligence, self-regulation, and leadership were not included among the top-endorsed character strengths of pilots. 
Table 1. Percentage of prevalence in which the strength is included in top-ranked ${ }^{*}$ and bottom-ranked ${ }^{\star}$ personal strengths among airline pilots $(\mathrm{N}=177)$.

\begin{tabular}{|c|c|c|c|}
\hline $\begin{array}{l}\text { Included in the five } \\
\text { top-ranked strengths }\end{array}$ & $\%$ & $\begin{array}{l}\text { Included in the five } \\
\text { bottom-ranked strengths }\end{array}$ & $\%$ \\
\hline Integrity & 62.7 & Spirituality & 95.4 \\
\hline Critical thinking & 43.5 & Zest & 46.3 \\
\hline Prudence & 39.5 & Bravery & 45.8 \\
\hline Love & 39.0 & Love of learning & 38.4 \\
\hline Fairness & 38.4 & Appreciation of beauty & 33.3 \\
\hline Creativity & 32.8 & Self-Regulation & 30.5 \\
\hline Perseverance & 27.1 & Forgiveness & 29.4 \\
\hline Teamwork & 22.6 & Creativity & 28.8 \\
\hline Curiosity & 22.6 & Social Intelligence & 28.8 \\
\hline Kindness & 22.6 & Humor & 27.7 \\
\hline Appreciation of beauty & 20.9 & Modesty & 27.1 \\
\hline Love of learning & 19.2 & Gratitude & 22.0 \\
\hline Forgiveness & 18.1 & Perseverance & 22.0 \\
\hline Humor & 18.1 & Hope & 18.6 \\
\hline Leadership & 11.9 & Perspective & 16.9 \\
\hline Self-Regulation & 11.3 & Prudence & 14.7 \\
\hline Perspective & 10.7 & Leadership & 13.6 \\
\hline Gratitude & 9.6 & Curiosity & 13.0 \\
\hline Hope & 9.0 & Love & 12.4 \\
\hline Bravery & 6.8 & Kindness & 10.7 \\
\hline Social intelligence & 6.8 & Teamwork & 10.2 \\
\hline Modesty & 5.1 & Fairness & 7.3 \\
\hline Zest & 1.7 & Critical thinking & 5.6 \\
\hline Spirituality & 0.6 & Integrity & 0.6 \\
\hline
\end{tabular}

${ }^{*}$ Note. Each participant has five top-ranked and five bottom-ranked strengths.

Second, VIA strengths scores were examined in their absolute magnitude (see Table 2). That is, for each character strength, we averaged the scores (1 to 5) given by all participants. Absolute scoring allows comparison of the magnitude of the various strengths among the pilots. The strengths scored highest by pilots were integrity ( $4.28 \pm 0.42)$, critical thinking ( $4.10 \pm 0.44)$, fairness (3.98 \pm 0.57$)$, love (3.97 \pm 0.58$)$, prudence ( $3.86 \pm 0.55)$, kindness ( $3.86 \pm 0.56$ ), and perspective $(3.81 \pm 0.52)$. Thus, we received further support for our hypothesis (H1) that integrity, critical thinking, and prudence are among the character strengths most endorsed by Israeli airline pilots. 
Table 2. Means and standard deviations of endorsed and used strengths by airline pilots and correlations of endorsed VIA strengths with life satisfaction, job satisfaction, and CRM skills $(\mathrm{N}=177)$.

\begin{tabular}{|c|c|c|c|c|c|c|}
\hline & $\begin{array}{c}\text { VIA } \\
M(S D)\end{array}$ & $\begin{array}{c}\text { SDM } \\
M(S D)\end{array}$ & $\operatorname{Diff}(t)$ & $\begin{array}{l}\text { Pearson } r \text { of } \\
\text { VIA with life } \\
\text { satisfaction }\end{array}$ & $\begin{array}{l}\text { Pearson } r \text { of } \\
\text { VIA with job } \\
\text { satisfaction }\end{array}$ & $\begin{array}{c}\text { Pearson } r \\
\text { of VIA with } \\
\text { CRM skills }\end{array}$ \\
\hline $\begin{array}{l}\text { Appreciation } \\
\text { of beauty }\end{array}$ & $3.50(0.79)$ & $2.86(0.96)$ & $-7.13^{\star *}$ & $.19^{*}$ & .13 & .08 \\
\hline Bravery & $3.30(0.61)$ & $2.30(0.90)$ & $-12.59^{* *}$ & .07 & .04 & .10 \\
\hline Creativity & $3.76(0.71)$ & $2.45(0.92)$ & $-15.31^{\star \star}$ & .06 & .07 & .04 \\
\hline Critical-thinking & $4.10(0.44)$ & $3.75(0.86)$ & $-5.12^{\star \star}$ & $.23^{*}$ & .05 & .07 \\
\hline Curiosity & $3.80(0.55)$ & $3.54(0.89)$ & $-3.39^{* *}$ & $.35^{* *}$ & $.16^{*}$ & $.22^{* *}$ \\
\hline Fairness & $3.98(0.57)$ & $3.43(0.88)$ & $-7.85^{\star \star}$ & .08 & .03 & .11 \\
\hline Forgiveness & $3.55(0.75)$ & $2.89(0.96)$ & $-7.54^{\star \star}$ & $.20^{*}$ & .02 & .11 \\
\hline Gratitude & $3.55(0.57)$ & $3.13(1.02)$ & $-5.30^{* \star}$ & $.29^{\star *}$ & $.17^{\star}$ & $.18^{*}$ \\
\hline Hope & $3.65(0.59)$ & $2.69(0.97)$ & $-12.18^{\star \star}$ & $.37^{\star *}$ & $.23^{*}$ & $.17^{\star}$ \\
\hline Humor & $3.62(0.73)$ & $3.10(0.88)$ & $-6.96^{* *}$ & $.16^{*}$ & $.18^{*}$ & -.03 \\
\hline Integrity & $4.28(0.42)$ & $3.95(0.87)$ & $-4.93^{\star *}$ & $.33^{* *}$ & .07 & .04 \\
\hline Kindness & $3.86(0.56)$ & $3.21(0.87)$ & $-9.27^{\star \star}$ & .07 & .10 & .07 \\
\hline Leadership & $3.77(0.56)$ & $3.82(0.97)$ & 0.76 & $.22^{*}$ & $.18^{*}$ & $.21^{*}$ \\
\hline Love & $3.97(0.58)$ & $2.76(0.96)$ & $-15.47^{\star \star}$ & $.15^{*}$ & .08 & .11 \\
\hline Love of learning & $3.60(0.73)$ & $3.84(0.79)$ & $3.16^{* *}$ & $.28^{\star *}$ & .09 & -.07 \\
\hline Modesty & $3.61(0.54)$ & $3.54(0.90)$ & -1.01 & .09 & -.01 & .01 \\
\hline Perseverance & $3.80(0.60)$ & $3.71(0.82)$ & -1.39 & $.22^{*}$ & .08 & .04 \\
\hline Perspective & $3.81(0.52)$ & $3.60(0.87)$ & $-2.96^{\star *}$ & $.16^{*}$ & $.15^{*}$ & .11 \\
\hline Prudence & $3.86(0.55)$ & $4.37(0.65)$ & $8.02^{* *}$ & $.21^{*}$ & .01 & .09 \\
\hline Self-regulation & $3.59(0.59)$ & $4.11(0.84)$ & $6.95^{\star *}$ & $.17^{\star}$ & -.01 & -.03 \\
\hline Social intelligence & $3.70(0.51)$ & $4.10(0.86)$ & $6.14^{* *}$ & $.19^{*}$ & 0.1 & $.17^{*}$ \\
\hline Spirituality & $2.43(0.75)$ & $2.97(1.12)$ & $5.51^{* *}$ & .15 & 0 & .07 \\
\hline Teamwork & $3.80(0.47)$ & $3.41(0.93)$ & $-5.53^{* *}$ & -.04 & .04 & .10 \\
\hline Zest & $3.54(0.58)$ & $3.09(0.94)$ & $-5.74^{\star *}$ & $.33^{* *}$ & $.25^{*}$ & $.18^{*}$ \\
\hline$M(S D)$ & & & & $5.18(0.94)$ & $5.57(0.78)$ & $8.31(0.60)$ \\
\hline
\end{tabular}

${ }^{*} p<.05,{ }^{* *} p<.01$.

On the other hand, the strengths most frequently endorsed as bottom-ranked strengths (being one of the personal five lowest strengths) by the pilots, as presented in Table 1, were spirituality (95.4\%), zest (46.3), bravery (45.8), love of learning (38.4\%), and appreciation of beauty and excellence (33.3\%). Those strengths receiving the lowest absolute scores were spirituality $(2.43 \pm 0.75)$, bravery (3.30 \pm 0.61$)$, appreciation of beauty $(3.50 \pm 0.79)$, forgiveness $(3.55 \pm$ $0.75)$, gratitude (3.55 \pm 0.57$)$, love of learning ( $3.60 \pm 0.73)$, and modesty (3.61 \pm 
0.54). Bravery was not found to be a strength characterizing airline pilots, either by ranking or by absolute scores.

\subsection{Differences between Endorsed and Deployed Character Strengths by Airline Pilots}

Our second hypothesis (H2) was that the strengths most used by pilots in their work will be the same strengths most endorsed by them. We found that the strengths most used by commercial airline pilots during their work were prudence $(4.37 \pm 0.65)$ and self-regulation $(4.11 \pm 0.84)$, while the strengths least used by pilots were bravery $(2.30 \pm 0.90)$ and creativity $(2.45 \pm 0.92)$.

In order to assess similarities and differences between endorsed (VIA-120) and used (SDM) strengths, $t$-tests for repeated measurements were conducted. VIA scores were significantly higher than SDM scores in appreciation of beauty, bravery, creativity, critical-thinking, curiosity, fairness, forgiveness, gratitude, hope, humor, integrity, kindness, love, perspective, teamwork, and zest $(-2.96<$ $t<15.47)$. SDM scores were higher than VIA scores in love of learning, prudence, self-regulation, social intelligence, and spirituality $(3.16<t<8.02)$.

\subsection{Associations between Endorsed Character Strengths and Life Satisfaction}

In order to examine $H 3$, we assessed associations between each one of the 24 VIA character strengths and life satisfaction by calculating Pearson correlations, as shown in Table 2. Low to moderate correlations were found between most strengths and life satisfaction $(.15<r<.36)$. Results pointed to hope, curiosity, zest, integrity, and gratitude as strengths most highly associated with life satisfaction. While hope, curiosity, zest, and gratitude were previously found as the strengths most highly associated with life satisfaction among large and diverse samples, integrity seems to be a unique contributor to airline pilots' life satisfaction.

\subsection{Associations between Endorsed Character Strengths and Job Satisfaction}

In order to examine $H 4$, we calculated Pearson correlations, between each of the 24 VIA character strengths and job satisfaction. As shown in Table 2, results pointed to curiosity, perspective, leadership, gratitude, hope, humor, and zest as associated with job satisfaction as an airline pilot $(.15<r<.25)$. Leadership was the only one of the eight hypothesized strengths found to be correlated with job satisfaction as an airline pilot.

\subsection{Character Strengths Which Serve as Predictors of CRM Actual Behaviors}

In order to examine $H 5$, we assessed associations, calculating Pearson correlations between VIA strengths and CRM actual behaviors. As shown in Table 2, self-assessed curiosity, social intelligence, leadership, gratitude, hope and zest, 
predict CRM actual behaviors, as assessed by colleagues $(.17<r<.22)$. All four hypothesized strengths were found to be predictors, with gratitude and hope also serving as predictors of CRM actual behaviors.

\section{Discussion}

The present study attempts to build a conceptual and empirical bridge between two worlds that have been studied only separately until now: the VIA model of character strengths and the profession of airline piloting. This study aimed to identify character strengths most highly endorsed by and most highly used in a typical work day of airline pilots, as well as strengths most highly associated with life and job satisfaction, and most predictive of CRM behaviors, specific work performance sought out attributes of airline pilots.

Life satisfaction for airline pilots was found to be most associated with character strengths of hope, curiosity, zest, integrity, and gratitude. Job satisfaction for airline pilots was found to be most associated with strengths of zest, hope, leadership, humor, and gratitude. Findings also highlighted the contributions of curiosity, leadership, gratitude, zest, hope, and social intelligence to CRM behaviors during flight.

Our findings pointed to integrity, critical-thinking, prudence, love, fairness, and creativity as strengths that more than $30 \%$ of the participating pilots possessed as signature strengths. Particularly noteworthy is the finding that integrity/honesty is one of the five most dominant strengths of more than $60 \%$ of the pilots. On the other hand, the five bottom-ranked strengths of more than $30 \%$ the participating pilots were spirituality, zest, bravery, love of learning, appreciating of beauty, and self-regulation. In order to ascertain the uniqueness of the piloting profession, we compared the pilots' most and least endorsed character strengths with those indicated by more than a million adults from 75 countries (McGrath, 2015). While fairness, integrity, and critical thinking were found to be the most frequent first-ranked strengths in the general population, prudence, as one of the five personally top-ranked (signature strengths), is unique to pilots. Moreover, prudence, a strength characterizing about $40 \%$ of the pilots, has been previously found as one of the least endorsed strengths in general population (McGrath, 2015). Regarding the low side of the hierarchy of strengths, while spirituality and zest were found to be among the lowest strengths also in the general population, bravery (and also love of learning and appreciation of beauty) being one of the five bottom-ranked strengths is unique to pilots. Thus, the uniqueness of the aviation pilot's profile emerging from this study is having prudence at the top and bravery at the bottom. This profile is consistent with the value of safety, which is the central value in commercial aviation. Pilots who do not place safety as their highest priority, by performing their duties at an excellent level, may bring themselves and the passengers to disaster (Oster et al., 2013). Aside from prudence, the pilots' full profile also comprises integrity, critical-thinking, love, fairness, and creativity. 
The findings of this study identify not only the pilots' strengths, but also the strengths they use at work. The strengths most used by pilots at work were prudence and self-regulation, while the strengths least used by pilots were bravery and creativity. Here again, prudence is at the top and bravery at the bottom. The greatest gaps between pilots' personal strengths and strengths applied at work appeared in the strengths of love, creativity, bravery, and hope, for which opportunities to use them at work as a pilot are substantially lower than would be indicated by their personal potential. However, love and hope are both associated with life satisfaction, and hope is associated with job satisfaction, a predictor of CRM behaviors. Nonetheless, the findings of this study support recommendations to distinguish between strengths endorsement and strengths deployment (Littman-Ovadia \& Steger, 2010).

Hope, curiosity, zest, and gratitude were found to be the strengths most highly associated with life satisfaction for pilots, similar to findings in the general population. However, integrity/honesty was found in the current study to be important for pilots' life satisfaction to a greater extent than for the general population. Taken together with being the most common signature strength of pilots, integrity/honesty no doubt plays a central role in this profession.

Our findings showed that job satisfaction as an airline pilot is associated primarily with zest, hope, leadership, humor, and gratitude. The current findings also highlighted the contributions of curiosity, leadership, gratitude, zest, hope, and social intelligence to CRM behaviors during flight.

It is noteworthy that of the five universal well-being strengths, four of them (curiosity, gratitude, hope, and zest) contribute to life satisfaction, job satisfaction, and CRM behaviors of pilots. However, leadership, as well as these four universal well-being strengths, has unique importance for pilots' desired job satisfaction and performance.

As a final conclusion of this study it should be noted that although some strengths contribute to a variety of desired outcomes, there are other strengths that have unique contributions to specific outcomes. For example, while zest, hope and gratitude are the most important character strengths for pilot's life satisfaction, job satisfaction and CRM behaviors during flight, leadership contributes only to work-related outcomes (job satisfaction and CRM behaviors during flight), and social intelligence contribute specifically to CRM behaviors during flight. Thus, specific strengths have to be cultivated in order to achieve specific results, yet there are strengths that help promote a range of desired outcomes in life and work as a pilot.

\section{Limitations and Future Research}

The current study provides a novel theoretical and empirical link between character strengths and aviation. Its methodology incorporated the evaluation of job performance by professional colleagues rather than by self-report, tapping actual CRM behaviors in multiple measurement events. However, this study suffers from some limitations that need to be addressed. Pilots' job performance was li- 
mited to CRM behaviors, neglecting other aspects of pilots' performance. An additional potential limitation of this study is the high scores in CRM behaviors given by colleagues with minimal variance. Finally, the long-term effects of strengths are unknown. Therefore, future studies should include additional measures of job performance, and additional raters of CRM behaviors, longitudinal data, and information about interventions targeting increased endorsement levels of desired strengths. Future studies should explore mediators (i.e., work meaning, work centrality, organizational climate and support) and their effects on pilots' job attitudes and performance.

Aside from the positive implications of identifying value profiles for various professions, research attention should be focused on professions functioning at more than one level, such as public sector vs. private sector, military vs. civilian. The general issue of employee-organization fit can be raised concerning the potential for smooth or rocky absorption of new employees, as professional workers enter an organization characterized by a culture different from their experience (e.g., does the culture prize innovation and creativity, self-regulation, or teamwork?). For instance, a personal strength reinforced in one organization may not be valued in another type of organization, which reinforces other values or strengths. Also, in this era of globalization, where frequent worker relocation is common, it would be important to investigate inter-cultural gaps within the same profession. Thus, upgrading candidate selection procedures by assessing personal strengths and determining their congruence with the desired organizational culture has the potential to facilitate positive organizational outcomes, such as worker engagement, satisfaction, and performance.

\section{Theoretical and Practical Implications}

The most important theoretical contribution of this research is building a conceptual bridge between the field of character strengths and the field of aviation. Combing the VIA model of character strengths with CRM and other constructs from the research on the profession of airline piloting, may expend the perspective of both domains: the VIA model to specific professions, and the field of aviation to the accumulated knowledge in positive psychology, which focuses on the optimal functioning.

This bridge paves the way for the development of practical tools for instructors and pilots flying commercial airliners. A key value of identifying character strengths in the work setting is by reinforcing or shaping the strengths beneficial for those possessing them. For instance, if pilots identify character strengths in a fellow pilot, they might highlight the events and occurrences where that strength was beneficial. When instructors train new pilots, they can reinforce those desirable character strengths they identify in their respective trainees, thus enhancing the latter's' self-awareness. These identified strengths can then be used to help each pilot focus on the positive aspects of their personality and skills. This would not only help their trainees to progress in their training, but also 
help them cope with failure.

For the general population of airline pilots, the findings of this research can be very productive upon thinking of "how I can improve my interpersonal (CRM) skills". If pilots understand that being curious about their own work, about their colleagues', and about their crew will contribute to their proficiency in CRM behaviors, they might find that inner strength and cultivate it. In other words, being aware of those character strengths regarding the explored aspects of this research can contribute to enhancement of work performance and satisfaction.

Finally, the deep understanding of the transition required of the pilot when shifting from military flying to commercial airline flying, from having a mission orientation to having a safety orientation, is found in our results and is most evident when looking at prudence as opposed to bravery. This reorientation to new Standard Operation Procedures (SOP) is critical for pilots as they take their first steps into the commercial aviation world.

Employers may find it useful to examine the extent to which they acknowledge and reinforce the universal well-being strengths among their workers. This may be a tool to enhance employee well-being, even in high-pressure surroundings and may serve to minimize worker turnover.

\section{Conflicts of Interest}

The authors declare no conflicts of interest regarding the publication of this paper.

\section{References}

Andrews, F. M., \& Withey, S. B. (1976). Social Indicators of Well-Being: The Development and Measurement of Perceptual Indicators. New York: Plenum. https://doi.org/10.1007/978-1-4684-2253-5

Ashcraft, K. L. (2005). Resistance through Consent? Occupational Identity, Organizational Form, and the Maintenance of Masculinity among Commercial Airline Pilots. Management Communication Quarterly, 19, 67-90. https://doi.org/10.1177/0893318905276560

Bienefeld, N., \& Grote, G. (2012). Silence That May Kill. Aviation Psychology and Applied Human Factors, 2, 1-10. https://doi.org/10.1027/2192-0923/a000021

Brooks, J. E. (2010). Midshipman Character Strengths and Virtues in Relation to Leadership and Daily Stress and Coping. Unpublished Doctoral Dissertation. Washington DC: Howard University.

Campbell, J. S., Castaneda, M., \& Pulos, S. (2010). Meta-Analysis of Personality Assessments as Predictors of Military Aviation Training Success. International Journal of Aviation Psychology, 20, 92-109. https://doi.org/10.1080/10508410903415872

Carretta, T. R. (1989). USAF Pilot Selection and Classification System. Aviation, Space and Environmental Medicine, 60, 46-49.

Carretta, T. R., \& Ree, M. J. (2003). Pilot Selection Methods. In P. S. Tsang, \& M. A. Vidulich (Eds.), Principles and Practice of Aviation Psychology (pp. 357-396). Mahwah, NJ: Erlbaum.

Carretta, T. R., Teachout, M. S., Ree, M. J., Barto, E. L., King, R. E., \& Michaels, C. F. 
(2014). Consistency of the Relations of Cognitive Ability and Personality Traits to Pilot Training Performance. Brooks AFB, TX: Human Effectiveness Directorate, Warfighter Training Research Division.

Diener, E., Emmons, R. A., Larsen, R. J., \& Griffin, S. (1985). The Satisfaction with Life Scale. Journal of Personality Assessment, 49, 71-75.

https://doi.org/10.1207/s15327752jpa4901_13

Engel, H. R., Westman, M., \& Heller, D. (2012). Character Strengths, Employees' Subjective Well Being and Performance: An Experimental Investigation. Unpublished Doctoral Dissertation. Tel-Aviv: Tel-Aviv University.

Flin, R., O'Connor, P., \& Mearns, K. (2002). Crew Resource Management: Improving Teamwork in High Reliability Industries. Team Performance Management: An International Journal, 8, 68-78. https://doi.org/10.1108/13527590210433366

Forest, J., Mageau, G. A., Crevier-Braud, L., Bergeron, E., Dubreuil, P., \& Lavigne, G. L. (2012). Harmonious Passion as an Explanation of the Relation between Signature Strengths' Use and Well-Being at Work: Test of an Intervention Program. Human Relations, 65, 1233-1252. https://doi.org/10.1177/0018726711433134

Harzer, C., \& Ruch, W. (2012). When the Job Is a Calling: The Role of Applying One's Signature Strengths at Work. Journal of Positive Psychology, 7, 362-371. https://doi.org/10.1080/17439760.2012.702784

Haavik, T. K., Kongsvik, T., Bye, R. J., Royrvik, J. O. D., \& Almklov, P. G. (2017). Johnny Was Here: From Airmanship to Airlineship. Applied Ergonomics, 59, 191-202. https://doi.org/10.1016/j.apergo.2016.08.028

Hedge, J. W., Bruskiewicz, K. T., Borman, W. C., Hanson, A. M., Logan, K. K., \& Frederick, M. S. (2000). Selecting Pilots with Crew Resource Management Skills. International Journal of Aviation Psychology, 10, 377-392.

https://doi.org/10.1207/S15327108IJAP1004_5

Lim, Y. J., \& Kim, M. N. (2014). Relation of Character Strengths to Personal Teaching Efficacy in Korean Special Education Teachers. International Journal of Special Education, 29, 53-58.

Linley, P. A., \& Harrington, S. (2006). Playing to Your Strengths. Psychologist, 19, 86-89.

Littman-Ovadia, H. (2015). Brief Report: Short Form of the VIA Inventory of Strengths-Construction and Initial Tests of Reliability and Validity. International Journal of Humanities Social Sciences and Education, 2, 229-237.

Littman-Ovadia, H., \& Lavy, S. (2012a). Character Strengths in Israel: Hebrew Adaptation of the VIA Inventory of Strengths. European Journal of Psychological Assessment, 28, 41-50. https://doi.org/10.1027/1015-5759/a000089

Littman-Ovadia, H., \& Lavy, S. (2012b). Differential Ratings and Associations with Well-Being of Character Strengths in Two Communities. Health Sociology Review, 21, 299-312.

Littman-Ovadia, H., \& Lavy, S. (2016). Going the Extra Mile: Perseverance as Key Character Strength at Work. Journal of Career Assessment, 24, 240-252.

https://doi.org/10.1177/1069072715580322

Littman-Ovadia, H., \& Steger, F. M. (2010). Character Strengths and Well-Being among Volunteers and Employees: Towards an Integrative Model. The Journal of Positive Psychology, 5, 419-430. https://doi.org/10.1080/17439760.2010.516765

Martinussen, M. (1996). Psychological Measures as Predictors of Pilot Performance: A Meta-Analysis. The International Journal of Aviation Psychology, 6, 1-20.

https://doi.org/10.1207/s15327108ijap0601_1 
McGrath, R. E. (2015). Character Strengths in 75 Nations: An Update. The Journal of Positive Psychology, 10, 45-52. https://doi.org/10.1080/17439760.2014.888580

Money, K., Hillenbrand, C., \& Camara, N. D. (2009). Putting Positive Psychology to Work in Organizations. Journal of General Management, 34, 21-26.

Nergard, V. (2014). Airmanship-A Qualitative Approach. Aviation, 18, 147-156. https://doi.org/10.3846/16487788.2014.969882

Nergard, V., Hatlevik, O. E., Martinussen, M., \& Lervag, A. (2011). An Airman's Personal Attitude: Pilot's Point of View. Aviation, 15, 101-111. https://doi.org/10.3846/16487788.2011.651789

Okray, R., \& Lubnau, T. (2003). Crew Resource Management for the Fire Service. Tulsa, OK: PennWell Books.

Orasanu, J., Fischer, U., \& Davison, J. (1997). Cross-Cultural Barriers to Effective Communication in Aviation. In C. C. Granrose \& S. Oskamp (Eds.), Cross-Cultural Work Groups (pp. 134-160). Thousand Oaks, CA: Sage.

Oster, C. V., Strong, J. S., \& Zorn, C. K. (2013). Analyzing Aviation Safety: Problems, Challenges, Opportunities. Research in Transportation Economics, 43, 148-164. https://doi.org/10.1016/j.retrec.2012.12.001

Park, N., \& Peterson, C. (2008). The Cultivation of Character Strengths. In M. Ferrari, \& G. Potworowski (Eds.), Teaching for Wisdom (pp. 57-75). Mahwah, NJ: Erlbaum.

Park, N., Peterson, C., \& Seligman, M. E. P. (2004). Strengths of Character and Well-Being. Journal of Social and Clinical Psychology, 23, 603-619. https://doi.org/10.1521/jscp.23.5.603.50748

Park, N., Peterson, C., \& Seligman, M. E. P. (2006). Character Strengths in Fifty-Four Nations and the Fifty US States. Journal of Positive Psychology, 1, 118-129. https://doi.org/10.1080/17439760600619567

Peterson, C., \& Park, N. (2006). Character Strengths in Organizations. Journal of Organizational Behavior, 27, 1149-1154. https://doi.org/10.1002/job.398

Peterson, C., \& Seligman, M. E. P. (2004). Character Strengths and Virtues: A Classification and Handbook. Washington DC: American Psychological Association.

Peterson, C., Ruch, W., Beermann, U., Park, N., \& Seligman, M. E. P. (2007). Strengths of Character, Orientations to Happiness, and Life Satisfaction. Journal of Positive Psychology, 2, 149-156. https://doi.org/10.1080/17439760701228938

Peterson, C., Stephens, J. P., Park, N., Lee, F., \& Seligman, M. (2010). Strengths of Character and Work. In P. A. Linley, S. Harrington, \& N. Garcea (Eds.), Oxford Handbook of Positive Psychology and Work (pp. 221-231). New York: Oxford University Press.

Pizzi, L., Goldfarb, N. I., \& Nash, D. B. (2001). Crew Resource Management and Its Applications in Medicine. In K. G. Shojania, B. W. Duncan, K. M. McDonald, \& R. M. Wachter (Eds.), Making Health Care Safer: A Critical Analysis of Patient Safety Practices (Chap. 44, pp. 511-519). AHRQ.

Seligman, M. E. P. (2011). Flourish: A Visionary New Understanding of Happiness and Well-Being. New York: Free Press.

Smith, M. R. (2011). The Relationship between Character Strengths and Work Satisfaction. Unpublished Doctoral Dissertation, Boston, MA: Massachusetts School of Professional Psychology.

Weber, D. E., Mavin, T. J., Roth, W. M., Henriqson, E., \& Dekker, S. W. (2014). Exploring the Use of Categories in the Assessment of Airline Pilots' Performance as a Potential Source of Examiners' Disagreement. Journal of Cognitive Engineering and Decision Making, 8, 248-264. https://doi.org/10.1177/1555343414532813 